\title{
CALCULATION-EXPERIMENTAL METHOD FOR DETERMINATION OF SPECTRUM COMPONENTS OF NON-STATIONARY LOADING OF CARBON STEEL WELDED JOINT
}

\author{
A.A. LUKASHEVICH \\ G.S. Pisarenko Institute for Problems of Strength, NASU \\ 2 Timiryazevskaya Str., 01014, Kiev, Ukraine. E-mail: ips@ipp.kiev.ua
}

\begin{abstract}
The time parameters of the spectrum components of non-stationary loading of welded joints of carbon steel were determined, having a dominant influence on the intensity of fatigue fracture of the structural elements of railway locomotives. A new method was offered for analysis of the results of strain gauge measuring of the evolution of deformation heterogeneity in the welded joint HAZ in the process of fatigue crack development. It was established that in each unit of loads at certain frequencies, the deformations exist which are dominant at fatigue fracture. 12 Ref., 5 Figures.
\end{abstract}

K e y w or d s : non-stationary loads, fillet welded joint, carbon steel, fatigue crack growth, strain gauge null-indicator method, time-frequency analysis

The parts and elements of structure of transport vehicles are subjected to non-stationary load during service, which is caused by many operational factors [1] (Figure 1).

The oscillation frequency of elements of mechanical structures of carriage parts of railway rolling stock is in the range from 1.5 to $110 \mathrm{~Hz}$ [2]. The complex character of force influence of the roadway on the carriage parts is determined by the fact that the frames of carriages, frames of bodies, carrying bodies represent

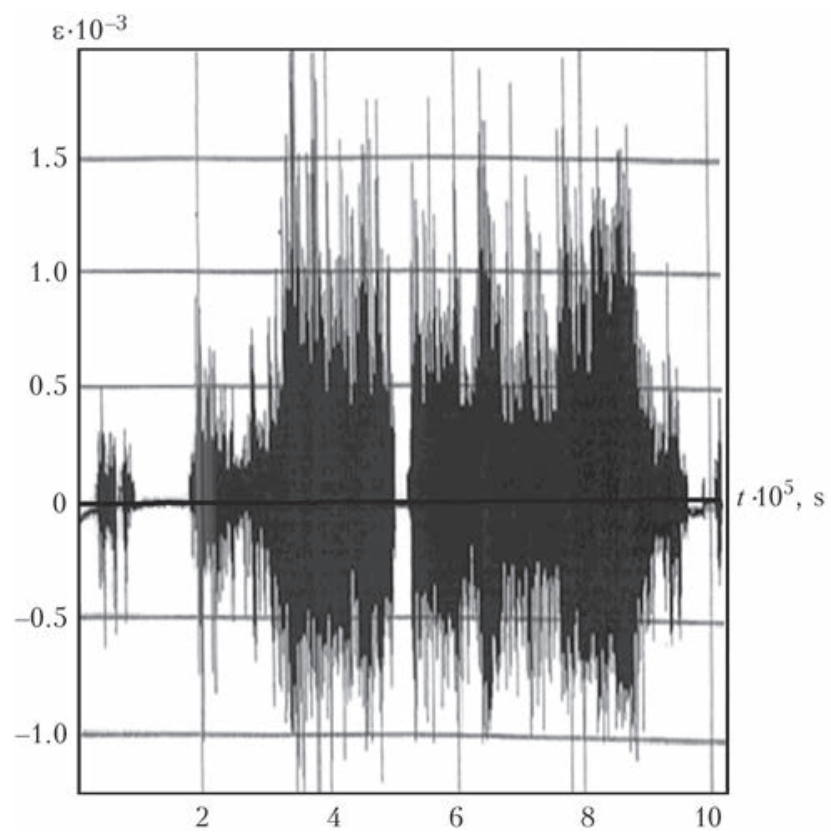

Figure 1. Spectrum of relative amplitudes of deformations of locomotive DS3 structural element during its service

(C) A.A. LUKASHEVICH, 2016 the oscillating systems with many degrees of freedom and their excitation factors bear a random character. The long-time service is accompanied by the occurring of fatigue fractures such as cracks, in particular, in welded joint, that makes the metal of this zone the most vulnerable to the fracture [3].

The aim of this work is the creation of discrete method for determination of spectrum of the oscillation frequencies, which are correlated with the maximum amplitudes of deformations of the surface areas of the investigated structural element or specimen being under control at their non-stationary loading.

Object and testing procedure. The work presents the testing results on cantilever bending in the mode of non-stationary loading of laboratory specimens of carbon steel St3sp (killed) [4] with fillet welded joints. The specimens of corset type of $3 \times 60 \times 165 \mathrm{~mm}$ size are manufactured according to the requirements of standard document [5], with fillet welded joint [6] and concentrator (Figure 2).

The sizes of mechanical concentrator, being experimentally determined (view $A$ in Figure 2) are as follows: $a^{\prime}=570.4_{-190.4}^{+141.6} \mu \mathrm{m}, b^{\prime}=309.4_{-104.4}^{+251.6} \mu \mathrm{m}$. Here $P_{1}$ - direction of force action on the specimen; and $\mathrm{S}-$ switch. Specimen 1 with load 3 was installed on bracket 2 (Figure 2).

On modernized vibration stand VEDS-400A [7], fatigue crack was grown to $3-7 \mathrm{~mm}$ size in the specimens near the concentrator at nominal stresses of 88-98 MPa of cantilever bending.

The spectrum of specimen loading, which corresponds to the typical spectrum of cycle frequencies 
in the range of $20-50 \mathrm{~Hz}$ (see Figure 1), is divided into three units according to the program, each having different duration. The loading is created by periodical movement of the vibrating table with amplitude of $\pm 8 \mathrm{~mm}$ in a certain frequency range.

The amplitude of deformations of the specimen surface was registered by strain gauges $\mathrm{T} 1$ and $\mathrm{T} 2$. In order to extend the dynamic range of sensitivity of the measuring system one of resistors $\mathrm{T} 2$ is located by its lattice towards the top of stress concentrator (see view $A$ in Figure 2). The growth of fatigue crack in welded joint was registered using strain gauge null-indicator method by measuring the difference of deformation amplitudes using strain gauges $\mathrm{T} 1$ and T2 [8]. To increase sensitivity the signal amplifier up to $U_{\max }=1500 \mathrm{mV}$ is installed in the system. The processing of measurement results was carried out using PC connected to device BVK-6 [9].

The deformation measurement results were stored on the flash-memory card of SD format. The information obtained as the separate files is recorded using the special program created on the basis of LabVIEW [10]. The number of units of the obtained information is defined by the volume of computer operative memory. After entering the experimental data into computer, the program displays the oscillograms of dependences of amplitudes deformation on time on the screen. The program runs with the information recognition frequency of 4096 points per second. On the computer monitor the oscillograms of oscillations and values of deformation amplitudes of the specimen with sampling frequency of $2048 \mathrm{p} / \mathrm{s}$ were displayed. The number of units where information is contained relatively to the deformation values measured in discrete points of the specimen surface is calculated by formula

$$
N_{\mathrm{u}}=N_{\text {inf }} /\left(N_{\mathrm{p}} / 2\right),
$$

where $N_{\mathrm{u}}$ is the number of units in the given volume of information; $N_{\text {inf }}$ is the amount of recorded information of complete sampling; $N_{\mathrm{p}}$ is the number of amplitudes of maximum deformation (determined by the number of points in one information unit).

Analysis of the obtained results. The difference of amplitudes $\Delta U$ of the signals received by means of strain gauges $\mathrm{T} 1$ and $\mathrm{T} 2$, is calculated by formula

$$
\Delta U=U_{\mathrm{T} 2}-U_{\mathrm{T} 1} \text {, }
$$

where $U_{\mathrm{T} 2}, U_{\mathrm{T} 1}$ is the drop of electric voltage at T2 and $\mathrm{T} 1$.

The difference of relative deformations amounted to

$$
\Delta \varepsilon=\Delta U M_{\varepsilon},
$$

where $M_{\varepsilon}=10^{-6} \mathrm{mV}^{-1}$ is the scale factor.

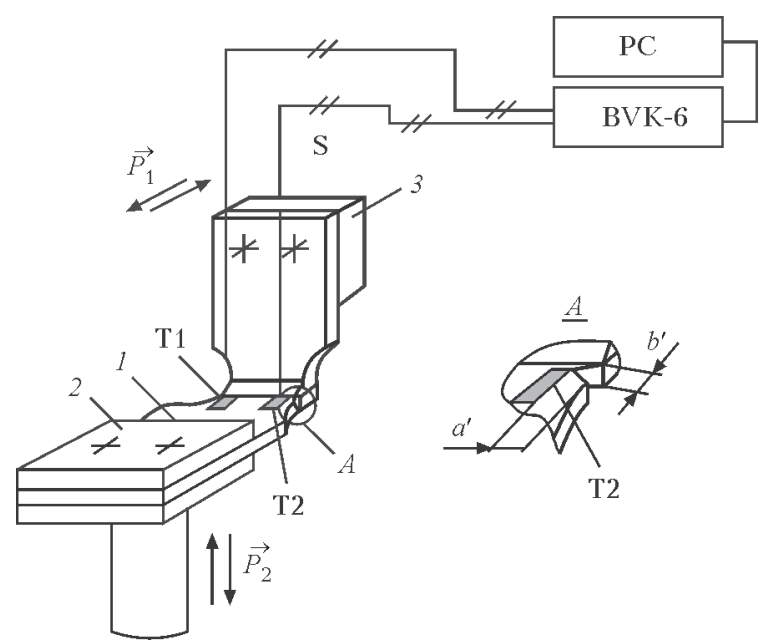

Figure 2. Scheme of loading the specimen on vibrating stand (designations see in the text)

The spectral analysis of units of relative deformation differences was realized using the method of wavelet transformation [11].

The wavelet transformation of $\Delta \varepsilon(t)$ signal has the following form [11]:

$$
\left[W_{\psi} \Delta \varepsilon\right](\tau, s)=\int_{-\infty}^{\infty} \Delta \varepsilon(t) \psi_{\tau, S}^{*}(t) d t,
$$

where $\tau$ is the time shift; $s$ is the scale; $\psi_{\tau, s}^{*}(t)$ is the Gauss mother wavelet [12]. Accepted that $\tau=250 \mathrm{~ms}$ and $s=0-150 \mathrm{~Hz}^{-1}$.

The mother wavelet is a function being the prototype of signal of all the scales $s$ generated during wavelet transformation $\left[\mathrm{W}_{\psi} \Delta \varepsilon\right](\tau, s)$ and which is selected by the operator separately for each phase of temporary shift of oscillation period, matching the greatest similarity of signal of the selected maternal function with the scale and temporary factors. The most widespread mother wavelets are built basing on the derivatives of Gauss function [12]:

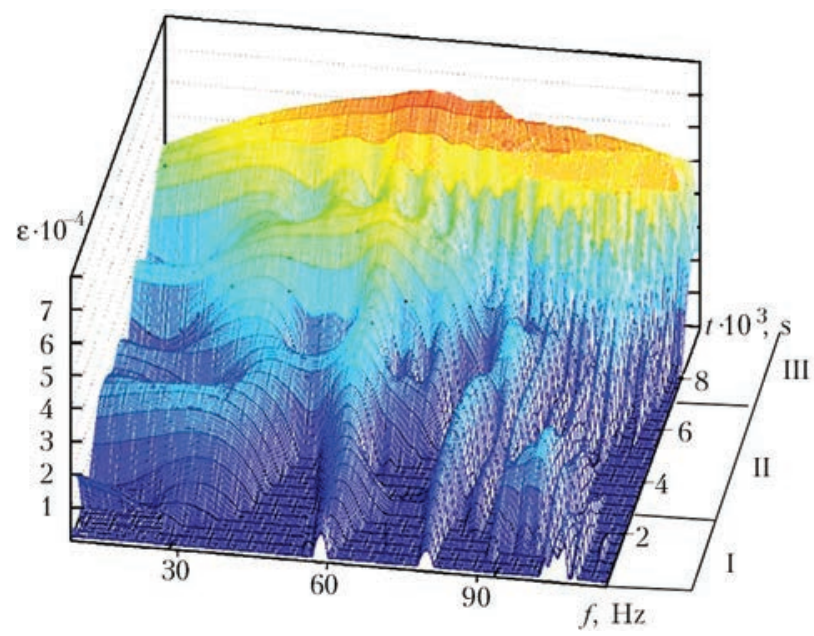

Figure 3. Volumetric wavelet-spectrum in $20-150 \mathrm{~Hz}$ frequency range of forced oscillations of fillet specimen of steel St3sp: I, II, III - time intervals corresponding to specific units of deformations 

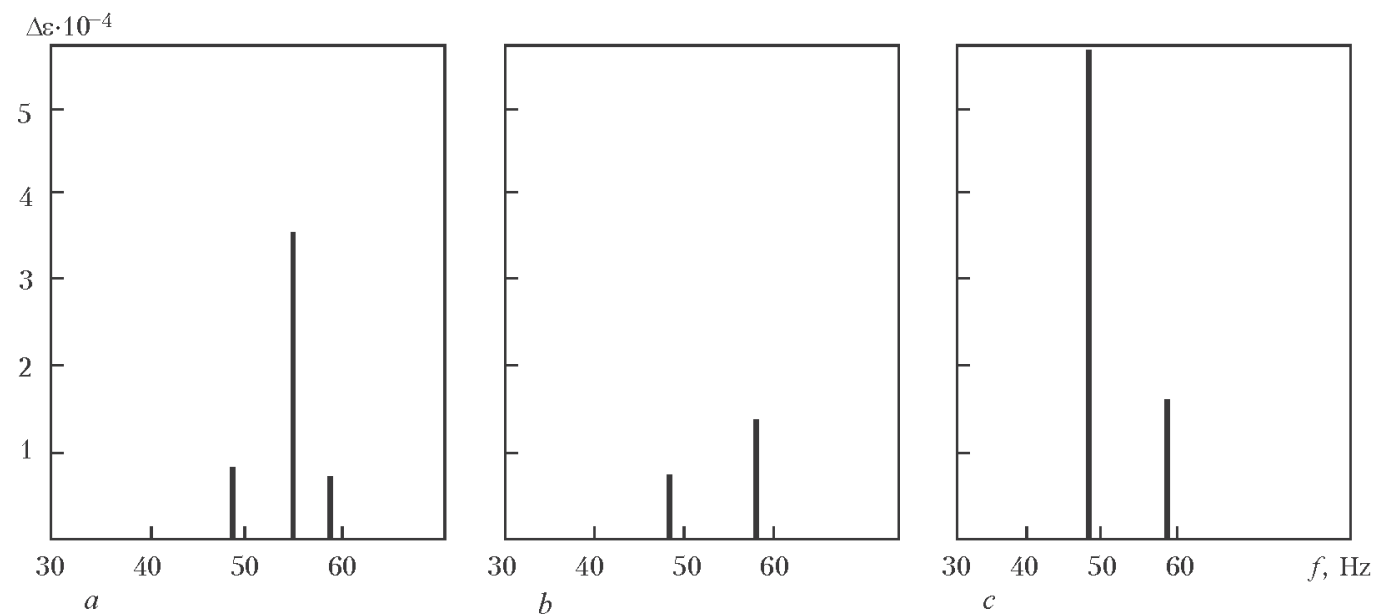

Figure 4. Difference of deformation amplitude versus frequency of specimen loading in units I (a), II (b) and III (c)
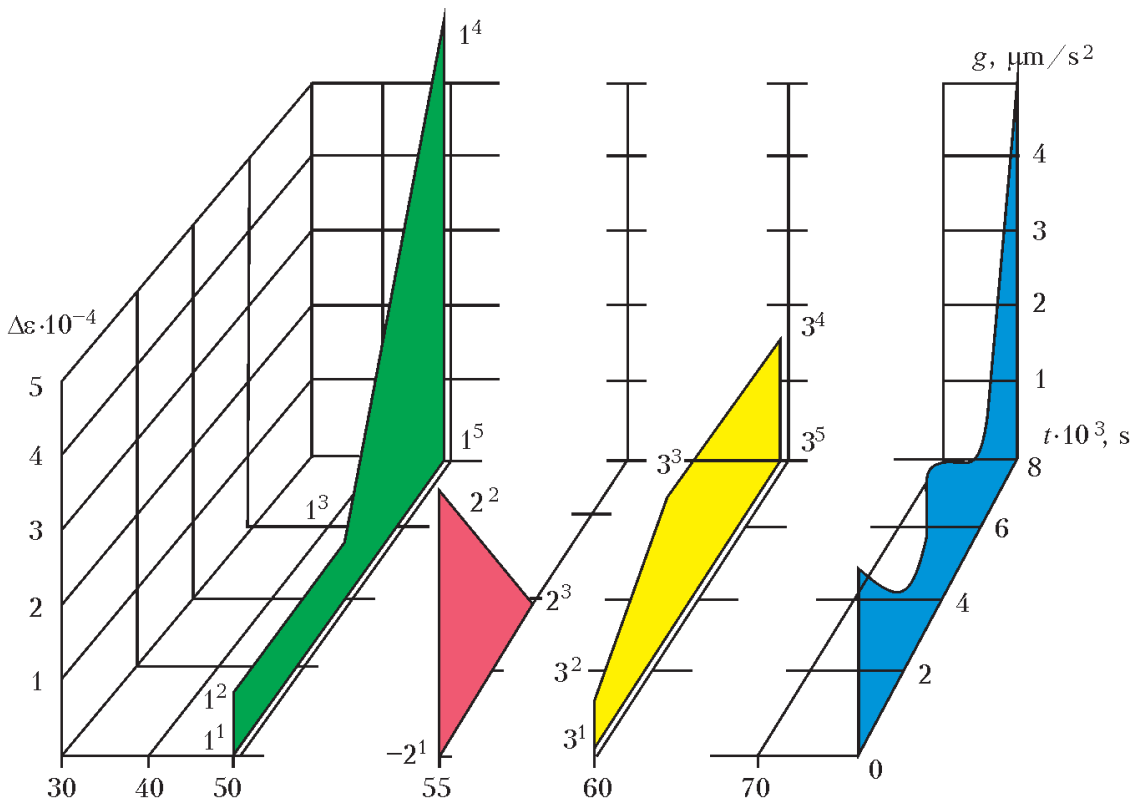

Figure 5. Distribution in time in different units of time-frequency analysis of dominant oscillation amplitudes of the specimen

$$
\psi_{\tau, s}^{*}(t)=\exp (-t / 2)
$$

In Figure 5 in three-coordinate measurements the distribution of deformation cycles in time with specific frequencies is given. In particular, for unit I -55 (plane $2^{1}-2^{2}-2^{3}$ ), for unit II -58 (plane $3^{1}-3^{2}-3^{3}-3^{4}$ ), for unit III $-48 \mathrm{~Hz}$ (plane $1^{3}-1^{4}-1^{5}$ ). 3D distribution of oscillation frequencies of the specimen in time for the units of frequency-phase analysis of deformation differences $\Delta \varepsilon$ are correlated with the distribution of accelerations $g$.

The representation of signal in three-coordinate form characterizes the duration of non-stationary loading process in time according to the action of deformation amplitudes of resonant splashes with specific frequencies and accelerations. $58 \mathrm{~Hz}$. The crack growth occurs at frequencies of 55 and $58 \mathrm{~Hz}$ at deformation unit I, and at 48 and $58 \mathrm{~Hz}$ at units II and III, respectively. It was revealed that for each unit the frequencies exist, for which the amplitude of the specimen deformation as a splash (wavelet) is dominant in the process of fatigue fracture.

\section{Conclusions}

1. On the model of the welded structure element the correlation between the maximum amplitudes of frequency spectrum and damaging splashes of differenc- 
es of deformations amplitude of the fillet specimen surface was determined.

2. The calculation experimental approach was offered for determination of dominant deformations based on the analysis of spectrum of frequencies of non-stationary loads, that creates new opportunities for improvement of methods of calculation of life of welded structural elements of transport vehicles.

1. Harris, W.J., Zakharov, S.M., Landgren, J. et al. (2002) General conclusions of advanced experience of heavy-loaded traffic: Problems of interaction between wheel and rail. $1^{\text {st }}$ ed. Moscow: In-tekst.

2. Basov, G.G., Falaleev, N.I., Yatsko, S.I. (2004) Modern methods of design of locomotive servicing parts. Zalizn. Transport Ukrainy, 4, 39-45.

3. Makhnenko, V.I. (2006) Resource of safe operation of welded joints and units of modern structures. Kiev: Naukova Dumka.

4. DSTU 2651-94: Ordinary carbon steel. Valid 01.01.96. Kyiv: Derzhstandart Ukrainy.
5. GOST 25.502-79: Calculations and strength tests in machine-building. Methods of mechanical tests of metals. Methods of strength tests. Valid 01.01.81. Moscow: Standart.

6. GOST 5264-80: Manual arc welding. Welded joints. Main types, structural elements and sizes. Valid 01.07.81. Moscow: Standartinform.

7. Troshchenko, V.T., Tsibanev, G.V., Gryaznov, B.A. et al. (2009) Fatigue of metals. Influence of surface state and contact interaction. Vol. 2. Kiev: IPP.

8. Leonets, V.A., Lukashevych, A.O., Degtyarev, V.O. et al. (2012) Assessment of the null-indicator method for the detection of fatigue cracks in structural elements. Strength of Materials, 44(3), 325-332.

9. Tokarev, O.D., Leonets, V.A., Leonets, A.A. et al. (2002) System of dynamic-strength tests of load-carrying structures of rolling stock and track structure at higher speeds of traffic. ZhD Transport Mira, 9, 73-76.

10. Travis, J., Kring, J. (2008) LabVIEW for all. Moscow: DMK Press.

11. Astafieva, N.M. (1996) Wavelet-analysis: Bases of theory and examples of application. Uspekhi Fizich. Nauk, 11, 1145-1170.

12. Diakov, V.P. (2002) Wavelet. From theory to practice. Moscow: Solon. 